\title{
Modeling and Investigation of Subsystems of Mechatronic Systems by Classic and/or Unclassic Methods as an Introduction to Solution of Their Inverse Task
}

\author{
Andrzej Buchacz \\ Faculty of Mechanical Engineering, Silesian University of Technology, Poland
}

Copyright (C) 2015 by authors, all rights reserved. Authors agree that this article remains permanently open access under the terms of the Creative Commons Attribution License 4.0 International License

\begin{abstract}
The problem of analysis within the form of the one differential equation of motion within the mechanical subsystem or of the set of state equations among considered mechatronic model of object has been formulated and solved. Classic and Galerkin's methods to solve the problem presented above have been used. The considered vibrating mechanical subsystems of mechatronic system are continuous bars of circular cross-section, with free ends or clamped on one end. The poles of dynamical characteristic calculated by mathematical exact method and the Galerkin's one have approximately the same values. The results of the calculations were not only presented in mathematical form but also as the transients of examined dynamical characteristic within function of frequency of assumed excitation. This approach is different from the ones considered so far. Using classic and unclassic methods among modeling, analysis and synthesis it can be assumed that the obtained results can have great value for designers of mechatronic system.
\end{abstract}

Keywords Vibrating Subsystems of Complex Mechatronic System, Modeling and Analysis, Exact and Approximate Methods

\section{Introduction}

The problems ${ }^{1}$ of modelling, synthesis and analysis of a continuous bar system and selected class of discrete mechanical systems concerning the frequency spectrum using classical and graphs [2] and structural numbers methods [1] has been conducted in the Gliwice research Centre (e.g. $[3-10,20,23,30])$. In [10-12] the continuous-discrete mechatronic system ${ }^{2}$, were considered

1Other diverse problems have been carried out by different kind of graphs next they were examined and analyzed in (e.g. $[3,13,20])$.

2 The problems concerned of piezoelectricity and electrostriction were presented for example in [27-29]. and the approximate method of analysis - Galerkin's method has been used in order to obtain the frequency -modal characteristics. The exact and Galerkin's method were used in [5] as a comparison of obtaining dynamical characteristics - dynamical flexibilities for mechatronic system. To compare the obtained dynamical characteristics - dynamical flexibilities only for mechanical transverse vibrating beam, being a parts of complex mechatronic systems, an exact method and the approximate methods were used [14-26]. Frequency analysis and frequency - modal analysis have been presented in this paper for the mechanical part of mechatronic system. To achieve the aim two methods of analysis have been used - the exact and Galerkin's approximate methods.

\section{The Exact and Approximate Methods Obtaining the Dynamical Flexibilities of Torsionally Vibrating Bars}

Different kind of shafts, clamped on the left end and free on the right one-CF, and free on the left and right end - FF, with the constant cross section were considered in this paper. The shaft is made of material with mass density $\rho$ and transverse modulus $G$, its inertia moment is $J$. The angle dislocation is $\varphi(x, t)$ within the time moment $t$ of the lining shaft section within the distance $x$ from the beginning of the system. The shaft is loaded with the harmonical moment $M(t)$ acting on the free end.

The equation of motion of the shaft equals:

$$
\frac{G I_{0}}{l} \frac{\partial^{2} \varphi}{\partial x^{2}}=J \frac{\partial^{2} \varphi}{\partial t^{2}}
$$

where: $c_{\varphi}=G I_{0} / l$ - torsional rigidity of the shaft, $I_{0}$ - polar inertia moment of the shaft cross section.

The boundary conditions on the shafts ends are as following: 


$$
\left\{\begin{array}{l}
\varphi=0 \text { when } x=0, \\
c_{\varphi} \frac{\partial \varphi}{\partial x}=M_{0} \cos \omega t \text { when } x=l,
\end{array}\right.
$$

After placing (6) into the boundary conditions (2) we receive

$$
\left\{\begin{array}{l}
A=0, \\
B=\frac{M_{0}}{c_{\varphi} \lambda \cos \lambda l} .
\end{array}\right.
$$

for FF ones.

Dislocation is the harmonic function because the excitation is the harmonic one, that

$$
\varphi(x, t)=X(x) \cos \omega t .
$$

Substituting following derivatives of (4) into (1) the following is obtained:

$$
c_{\varphi} \frac{\partial^{2} X}{\partial x^{2}}+J \omega^{2} X=0
$$

The solution of expression (5) can be obtained as following form:

$$
X(x)=A \cos \lambda x+B \sin \lambda x,
$$

where: $A$ and $B$ are any optional real constants and

$$
\lambda l=\omega \sqrt{\frac{I}{c_{\varphi}}} .
$$

The dislocation of the section $x$ of the shaft - after substituting (8) into (4) is presented as following:

$$
\varphi(x, t)=\frac{\sin \lambda x}{c_{\varphi} \lambda \cos \lambda l} M_{0} \cos \omega t
$$

From equation (9) the dynamical flexibility is equal

$$
Y_{x l}=\frac{\sin \lambda x}{c_{\varphi} \lambda \cos \lambda l}
$$

When $x=l$ dynamical flexibility takes following form

$$
Y_{l l}=\frac{1}{c_{\varphi} \lambda} \operatorname{tg} \lambda l .
$$

Repeating the procedure of determining the dynamic flexibility for boundary conditions (3) we obtain

$$
Y_{l l}=\frac{1}{c_{\varphi} \lambda} \operatorname{ctg} \lambda l .
$$

The absolute value transients of expressions (11) and (12) are shown in Fig. 1 and 2. In the next figures the transients obtained by exact method will be marked with blue colour.

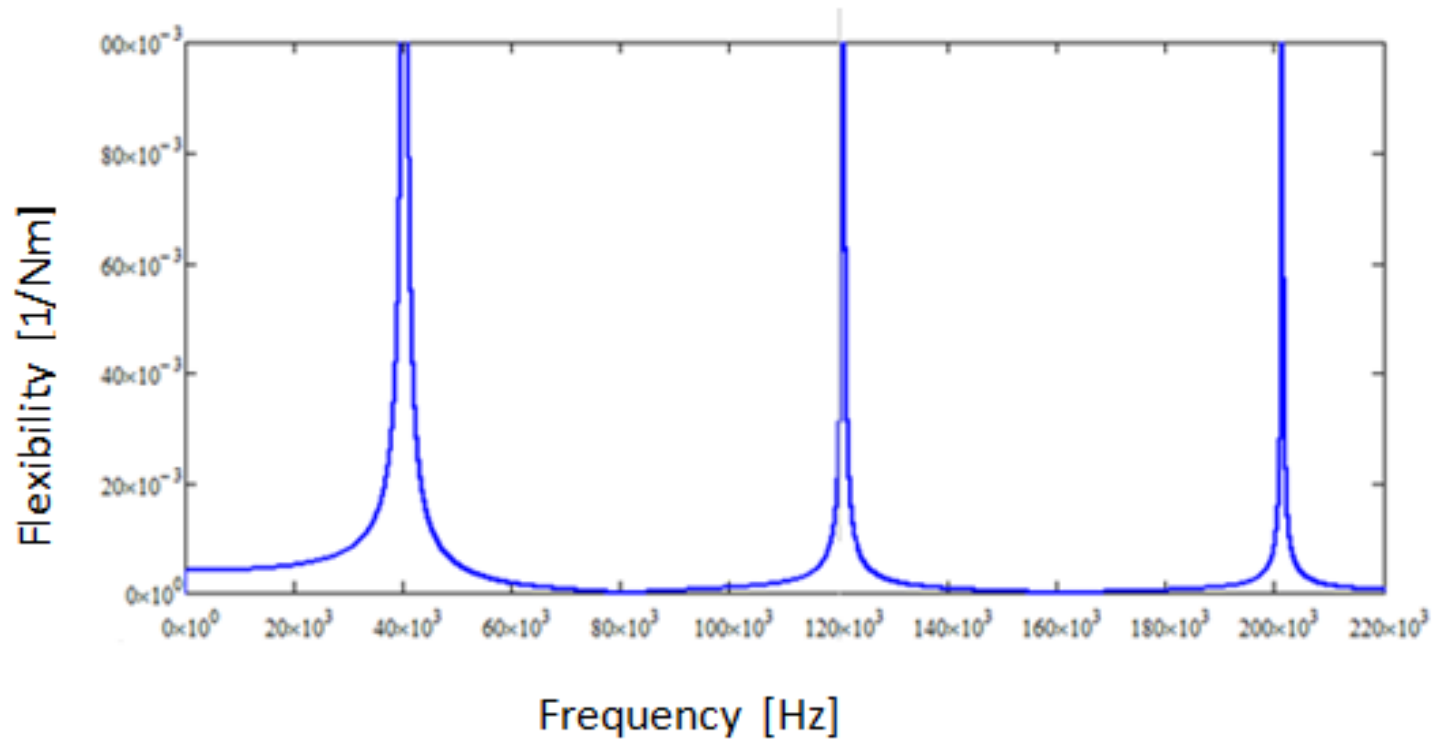

Figure 1. The transient of flexibility (11) - the exact method 


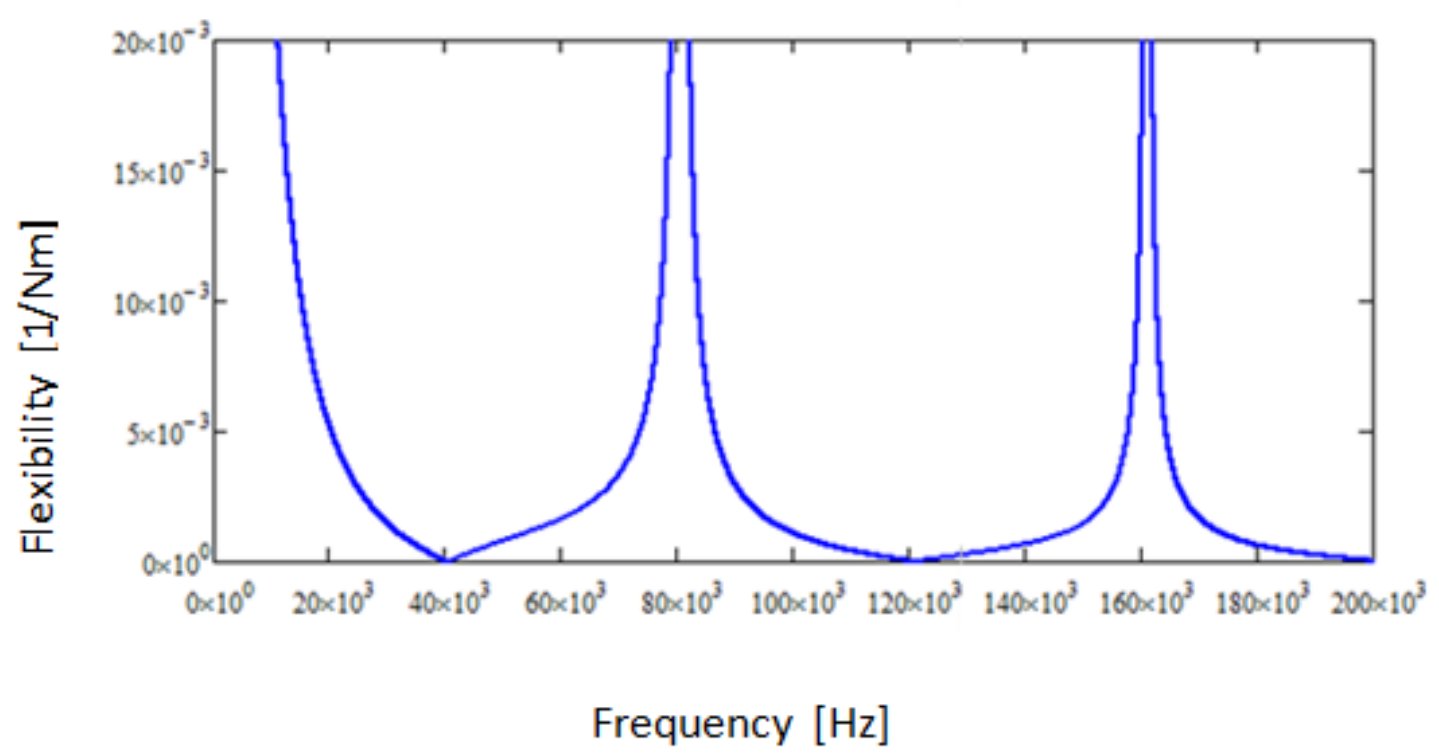

Figure 2. The transient of flexibility (12) - the exact method

Received transients of flexibilities within the models of mechanical subsystems, obtained by the exact method, will be treated as the course to which the transients, obtained by the approximate of mechanical system, will be compared (e.g. [10-12]).

According to the Galerkin's method, that means approximate one, the final solution will be searched within the sum of functions, which will respond to the variables of the time and dislocation, which are strictly accepted and fulfill the boundary conditions in form (2) and (3).

Using the Galerkin's method, the solution of the equation (1) is given in the following form for boundary conditions (2):

$$
\begin{aligned}
& \phi(x, t)=\sum_{k=1}^{\infty} \phi_{k}(x, t)= \\
& =A_{k} \sum_{k=1}^{\infty} \sin \frac{(2 k-1) \pi x}{2 l} \cos \omega t .
\end{aligned}
$$

Substituting the following derivatives of (13) into the equation of motion is following

$$
\begin{aligned}
& -c_{\varphi} A_{k}\left[(2 k-1) \frac{\pi}{2 l}\right]^{2} \sin \frac{(2 k-1) \pi x}{2 l} \cos \omega t+ \\
& +J A_{k} \omega^{2} \sin \frac{(2 k-1) \pi x}{2 l} \cos \omega t=M_{0} \cos \omega t .
\end{aligned}
$$

Making appropriate transformations the dynamical flexibility equals

$$
Y_{x l}=\sum_{k=1}^{\infty} Y_{x l}^{(k)}=\sum_{k=1}^{\infty} \frac{\sin \left[(2 k-1) \frac{\pi}{2 l} x\right]}{J \omega^{2}-c_{\phi}\left[(2 k-1) \frac{\pi}{2 l}\right]^{2}}
$$

The Galerkin's method of the solution within the equation (1) for boundary conditions (3) is given in the following form

$$
\begin{aligned}
& \phi(x, t)=\sum_{k=1}^{\infty} \phi_{k}(x, t)= \\
& =A_{k} \sum_{k=1}^{\infty} \cos \frac{(2 k-1) \pi x}{2 l} \cos \omega t .
\end{aligned}
$$

Making the suitable operations on (16), after transformations, the dynamical flexibility is equal

$$
Y_{x l}=\sum_{k=1}^{\infty} Y_{x l}^{(k)}=\sum_{k=1}^{\infty} \frac{\cos \left[(2 k-1) \frac{\pi}{2 l} x\right]}{J \omega^{2}-c_{\phi}\left[(2 k-1) \frac{\pi}{2 l}\right]^{2}} .
$$

The absolute values of plots of expressions (15) and (17), for $x=l$ have been presented for example in Fig. 3 and 4 . 


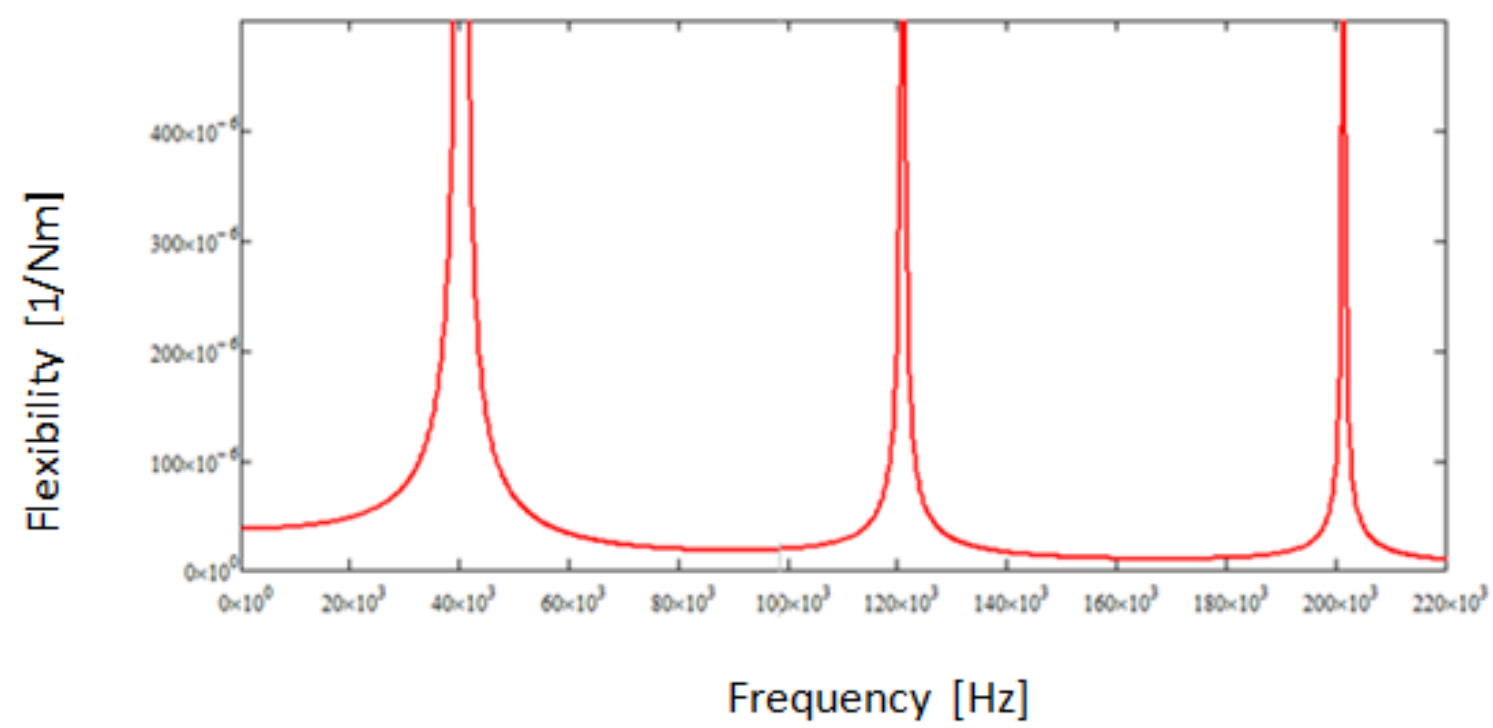

Figure 3. The transient of absolute value of flexibility (15)

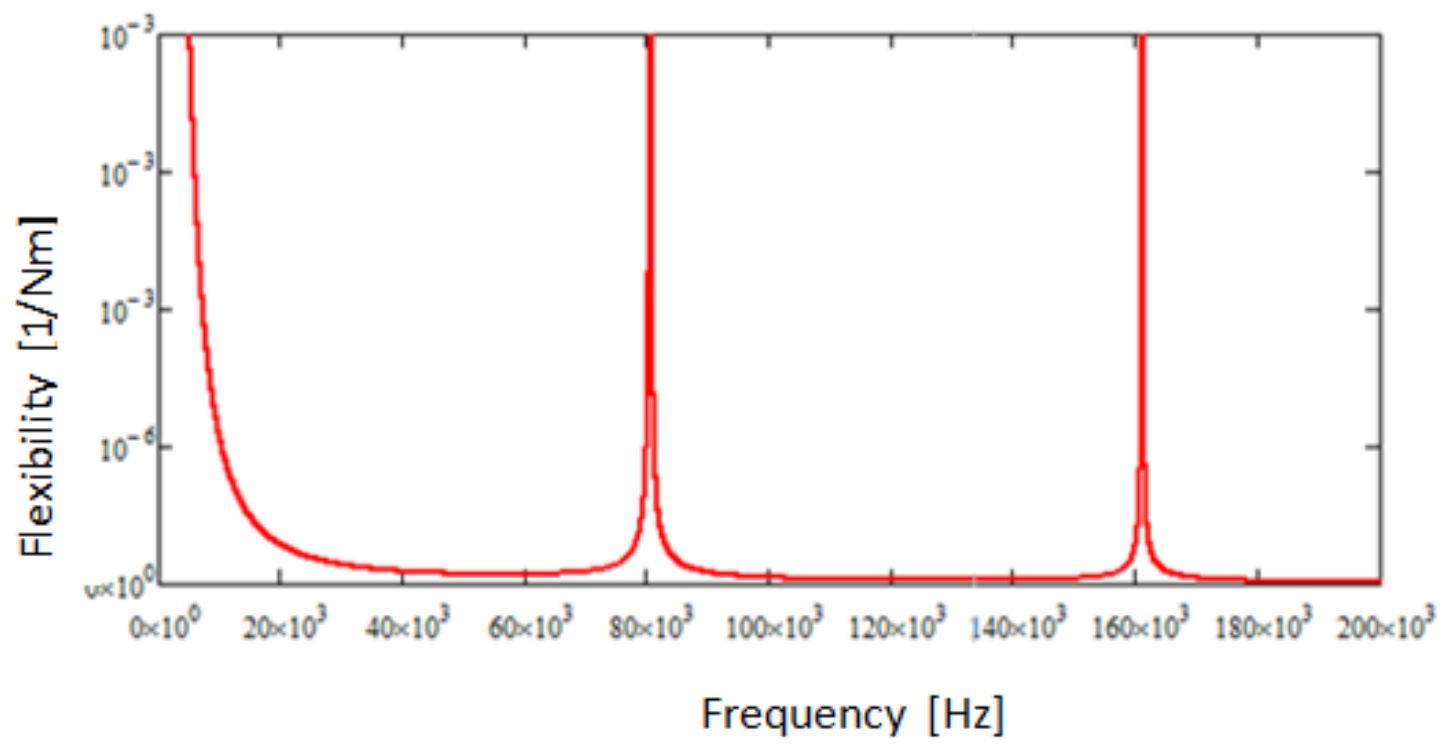

Figure 4. The transient of absolute value of flexibility (17)

In the next figures the transients obtained by Galerkin's method will be marked by red colour. The plots of dynamical flexibilities obtaining by exact and approximate method are shown in figures 5 and 6 . 


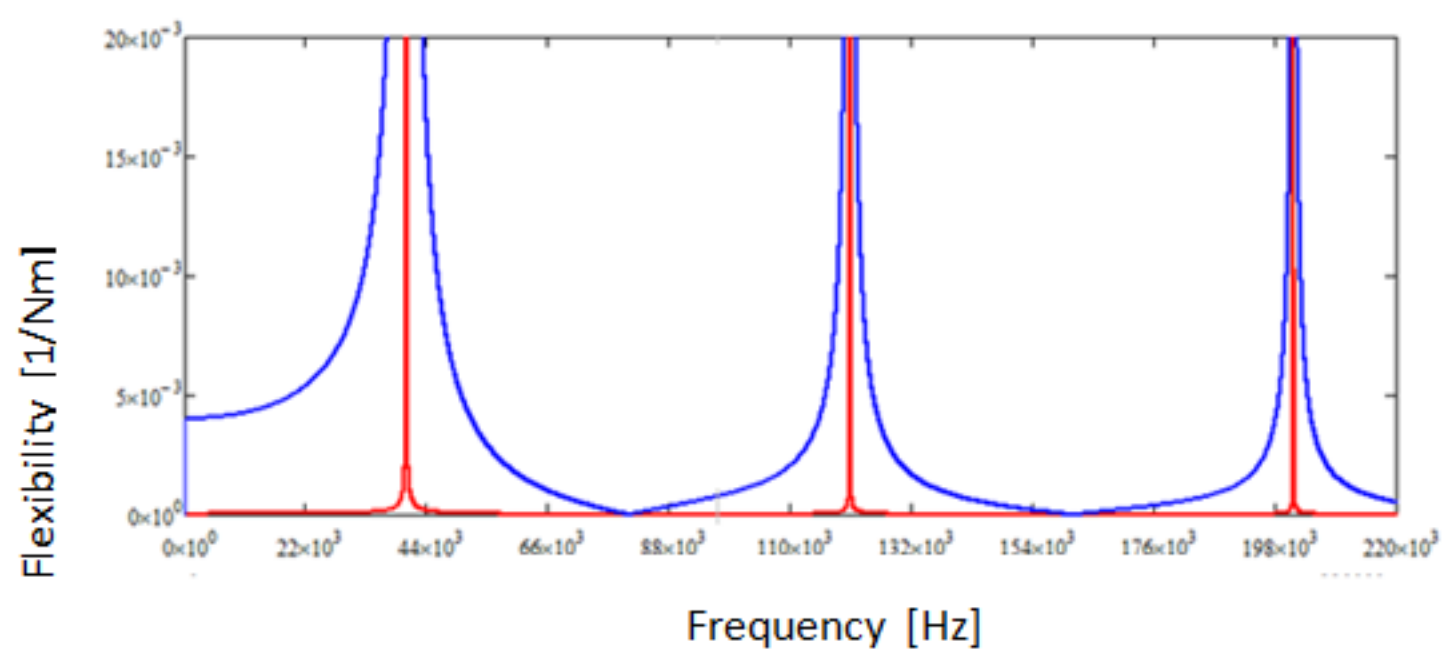

Figure 5. Dynamical flexibilities of CF bar - comparison of exact and approximate methods

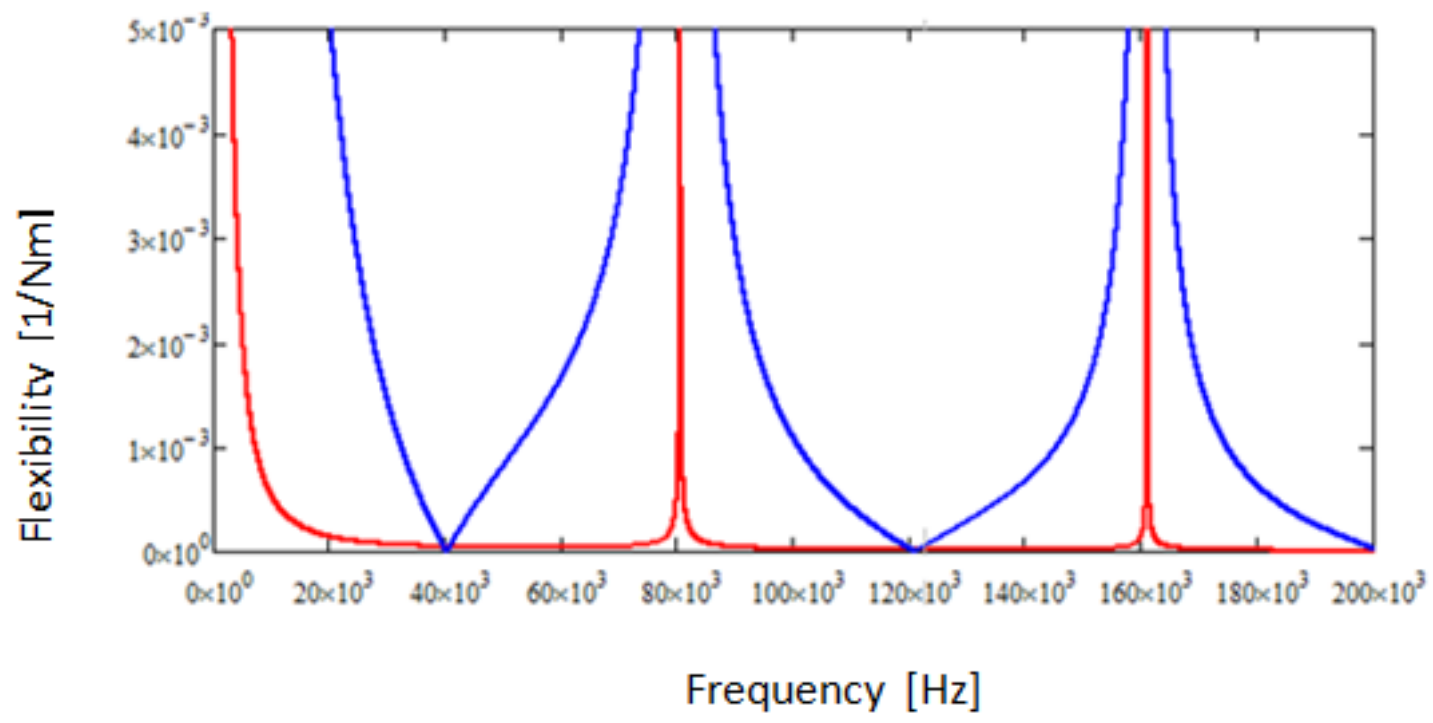

Figure 6. Dynamical flexibilities of FF bar - comparison of exact and approximate methods

The transients of flexibilities, received with exact and approximate methods, were shown in Fig. 5. It is very important to notice, that values of theirs poles are the same. For remaining frequencies the values of flexibilities are different. These differences were presented in Fig. 7 and 8.

Analyzing the flexibility transients of considered bars it can be assumed, that in the case of approximate method the resonance frequencies are covering with the exact method. However the flexibilities values in other areas are considerably different. There is also the mistake of approximate method, which during the exploration of the single bars does not have any influence, because in resonance areas the flexibility of the structure aims towards infinity in both methods. The differences in flexibility values of both methods have big influence on the synthesis results of complex mechanical or mechatronic complex systems. That is why it was necessary to correct the values of approximate method.

The coefficient of correction $\lambda$ was determined according to dependence

$$
\lambda=\frac{Y_{d}(f)}{Y_{p}(f)} .
$$




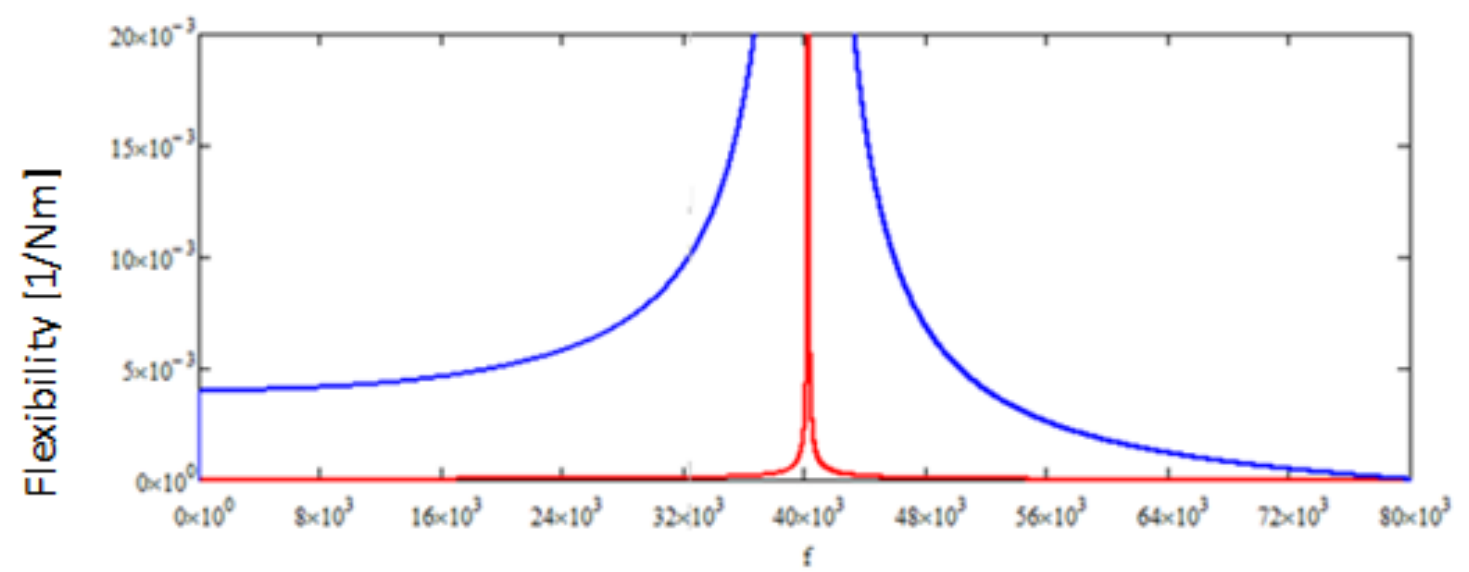

\section{Frequency $[\mathrm{Hz}]$}

Figure 7. Dynamical flexibilities of CF bar - comparison of exact and approximate methods for first vibration frequency

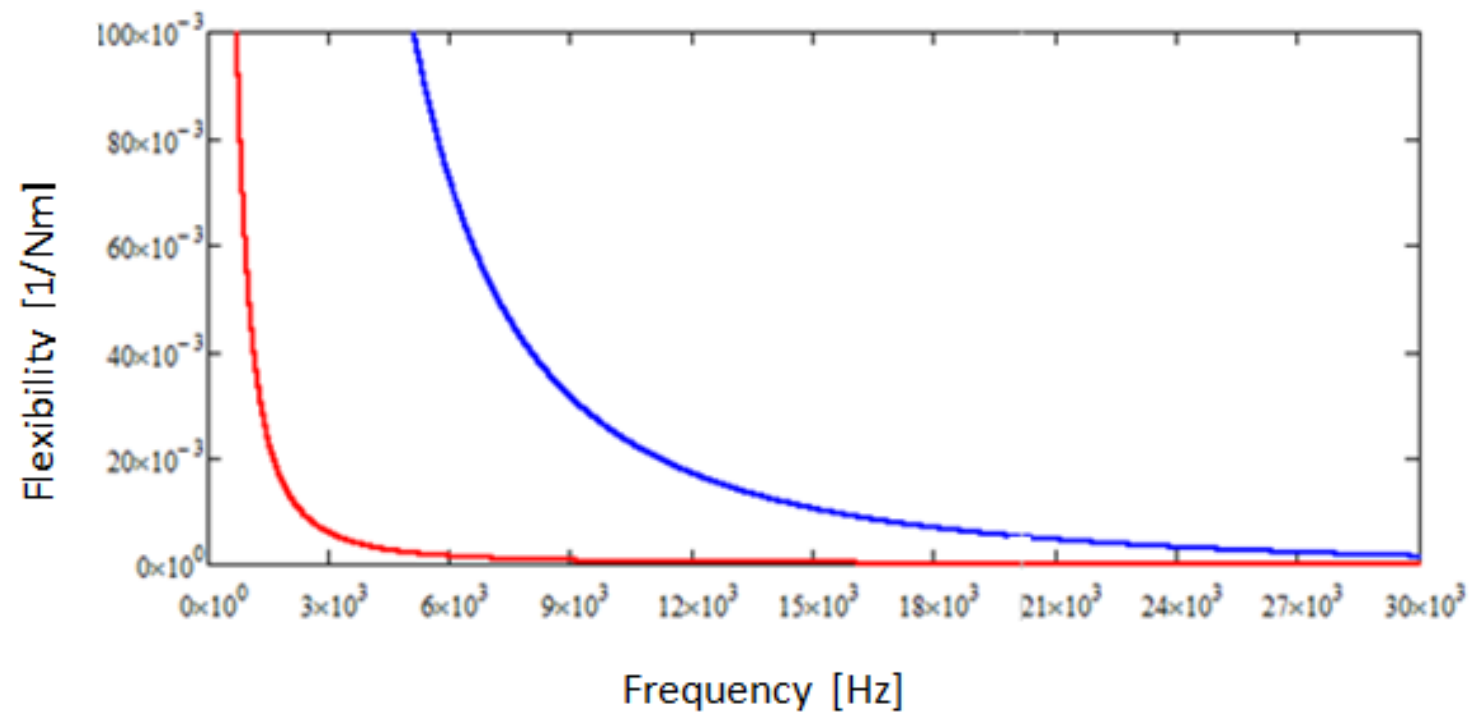

Figure 8. Dynamical flexibilities of FF bar - comparison of exact and approximate methods for first vibration frequency

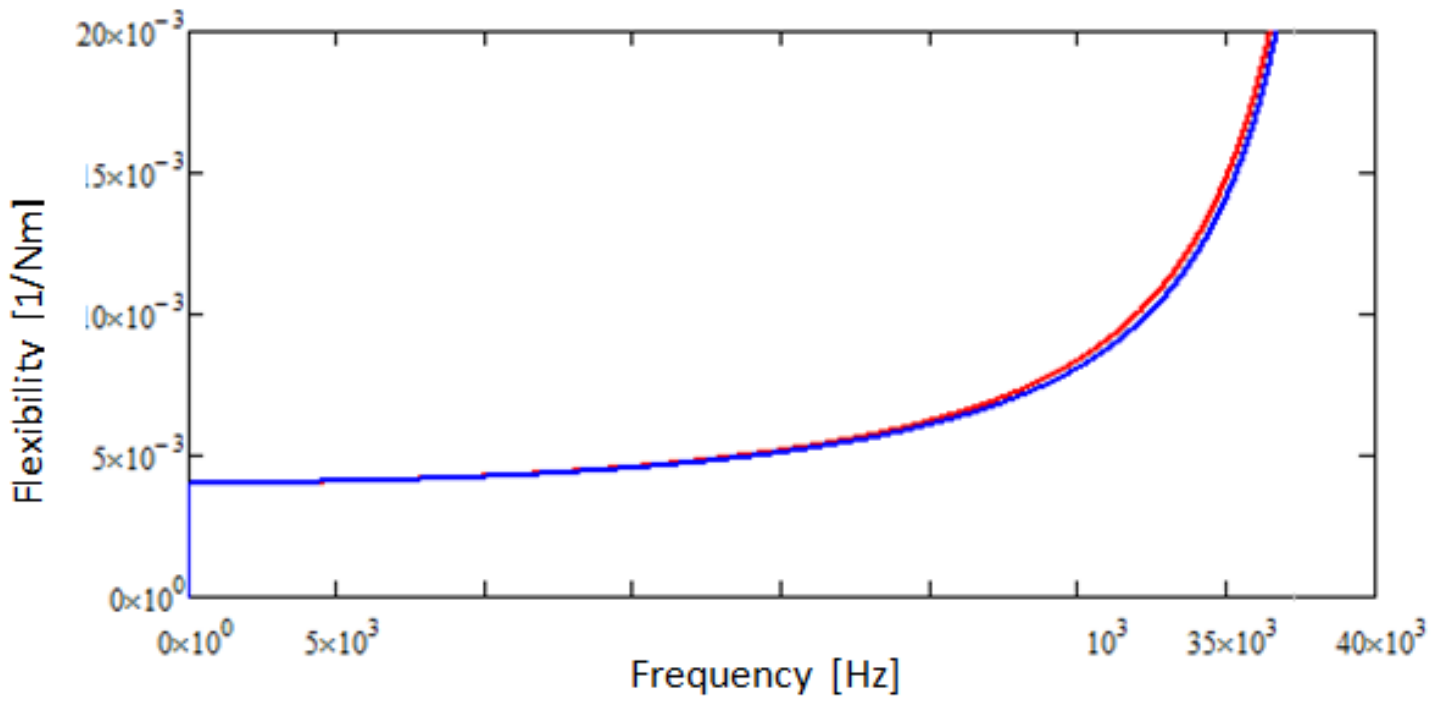

Figure 9. Dynamical flexibilities of CF bar after correction of approximate method 


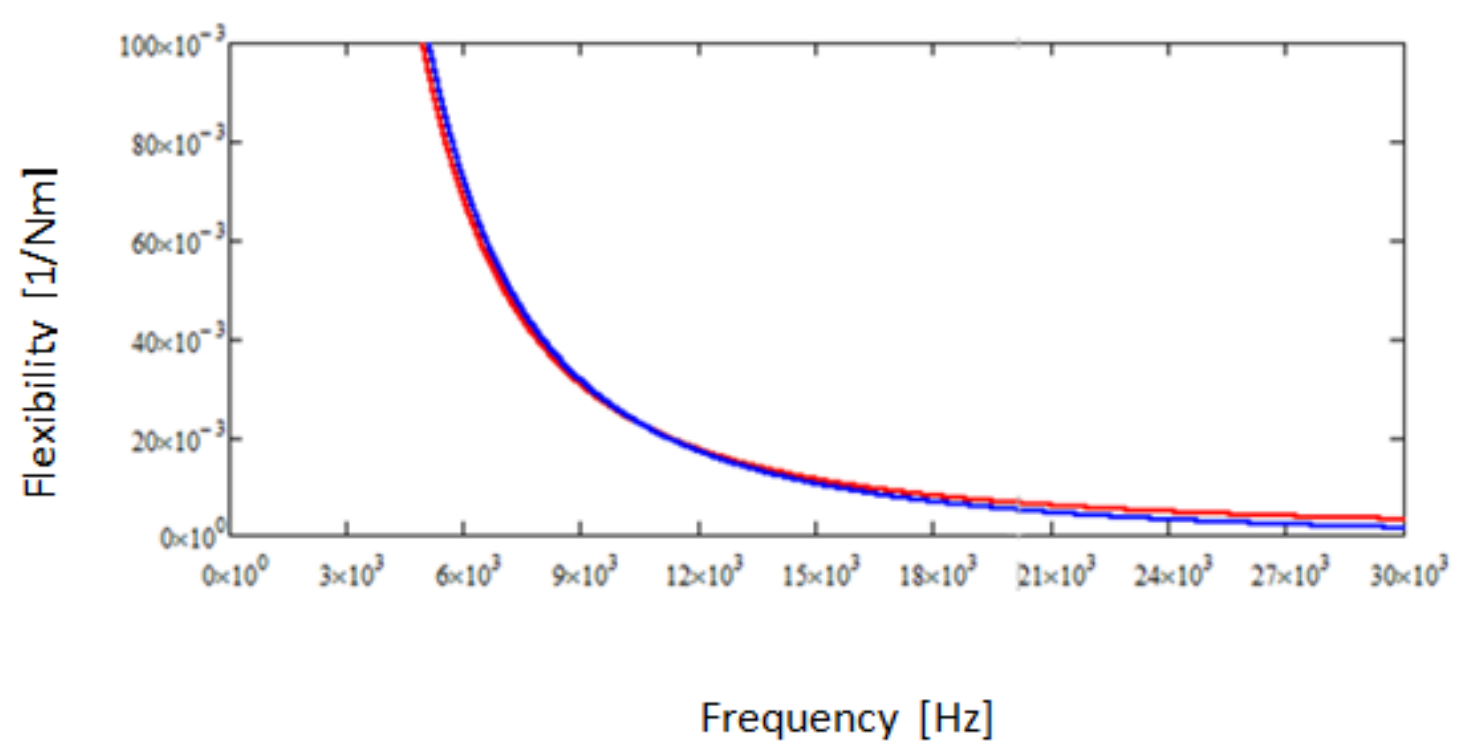

Figure 10. Dynamical flexibilities of FF bar after correction of approximate method

Determined in accordance to the dependence (18) - in the range of frequency $\{0,30 \mathrm{kHZ}\}$ - the correction coefficients amount to: $\lambda=107$ as far as the strengthened shaft is concerned and $-\lambda=46$ in the reliance to free shaft. The corrected course of dynamic susceptibility is presented in the figures 9 and 10.

The corrected dependencies of mechatronic subsystems are the foundation to solve the problem of reverse torsionally vibrating continuous - discrete complex mechatronic systems.

\section{Conclusions}

Applied methods and obtained results as well as using graph and hypergraph and their connections with structural numbers $[1,2]$ and the system of notation $[5,30]$, can be the introduction to the synthesis of torsionaly vibrating mechatronic systems with a constant changeable cross-section. There are some numerical implementations [18] enabling to solve the considered systems. However, these problems shall be discussed in future research works.

\section{Acknowledgements}

This work has been conducted as a part of research project PBS2/A6/17/2013 supported by the National Centre for Research and Development in 2013-2016.

\section{REFERENCES}

[1] S. Bellert, H. Woźniacki: The analysis and synthesis of electrical systems by means of the method of structural numbers [in Polish]. WNT, Warszawa 1968.
[2] C. Berge: Graphs and hypergraphs. American Elsevier Publishing Co., Inc., New York/ North Holland Publishing Co., Amsterdam-London 1973.

[3] K. Białas, A. Buchacz, T. Dzitkowski: Synthesis of active mechanical systems with dumping inview of polar graphs and structural numbers. Monograph No. 230. Silesian University of Technology Press, Gliwice 2009 (in Polish).

[4] A. Buchacz: Modelling, synthesis and analysis of bar systems characterized by a cascade structure represented by graphs. Mech. Mach. Theory, 30, 7, 969-986, Pergamon, 1995.

[5] A. Buchacz: The Synthesis of Vibrating Bar-Systems Represented by Graph and Structural Numbers. Scientific Letters of Silesian University of Technology, MECHANICS, z. 104, Silesian University of Technology Press 1991 (in Polish).

[6] A. Buchacz, A. Dymarek, T. Dzitkowski: Design and examining of sensitivity of continuous and discrete-continuous mechanical systems with required frequency spectrum represented by graphs and structural numbers. Monograph No. 88. Silesian University of Technology Press, Gliwice 2005 (in Polish).

[7] A. Buchacz: The expansion of the synthesized structures of mechanical discrete systems represented by polar graphs. Journal of Materials Processing Technology. Vol. 164-165, Complete Elsevier, (2005), p.1277-1280.

[8] A. Buchacz, Żurek K.: Reverse task of dynamice of active mechanical systems by means the graphs and structural numbers methods. Monograph No 81. Silesian University of Technology Press, Gliwice 2005 (in Polish).

[9] A. Buchacz: Modelling, synthesis, modification, sensitivity and analysis of mechanic and mechatronic systems. Journal of achievements in materials and manufacturing engineering, International OCOSCO World Press, Vol. 24, Issue 1, September 2007, p. 198-207.

[10] A. Buchacz: Dynamical flexibility of discrete-continuous vibrating mechatronic system. Journal of Achievements in Materials and Manufacturing Engineering, International OCOSCO World Press,Vol. 28, Issue 2, January 2008, p. 
159-166.

[11] A. Buchacz: Characteristics of discrete-continuous flexibly vibrating mechatronic system. Journal of Achievements in Materials and Manufacturing Engineering, International OCOSCO World Press, Vol. 28, Issue 1, May 2008, p. 43-46.

[12] A. Buchacz: Calculation of Flexibility of Vibrating Beam as the Subsystem of Mechatronic System by Means the Exact and Approximate Methods. PAMM - Proc. Appl. Math. Mech. 9, Issue 1, 373 - 374 (2009) WILEY-VCH Verlag GmbH \& Co. KgaA, Weinheheim, Published Online: 5 Mart 2010 DOI 10.1002/pamm.200910160

[13] A. Buchacz: Transformations of Hypergraphs of Beams as Models in Synthesis of Flexibly Vibrating Continuous Mechanical Systems. Vestnik Krymskoy Akademii Nauk Sevastopolskie otdelenie. Release 1. Sevastopol 2010, p. 35-38.

[14] A. Buchacz: Orthogonalization Method of Analysis of Mechanical And Mechatronic Systems. LES PROBLÈMES DU TECHNOSHĖRE ET DE LA FORMATION DES CADRES D'INGÉNIEURS CONTEMPORAINS, Recueil des exposés des participants du III Séminaire international scientifique et méthodique, Novembre 2009 à Sousse (Tunisie), Donetsk (2009), p. 85-88.

[15] A. Buchacz: Comparision of Characteristics of Subsystems and Systems as Introduction to Synthesis of Torsionally Vibrating Mechatronic Systems. LES PROBLÈMES DU TECHNOSHËRE ET DE LA FORMATION DES CADRES D'INGÉNIEURS CONTEMPORAINS, Recueil des exposés des participants du IV Séminaire international scientifique et méthodique, Novembre 2010 à Hammamet (Tunisie), Donetsk (2010), p. 85-88.

[16] A. Buchacz: Modeling and Analysis of Beams by Means the Exact and Approximate Methods as Formal Set into Their Synthesis. Vestnik Krymskoy Akademii Nauk Sevastopolskie otdelenie. Release 2. Sevastopol 2011, p. 30-34.

[17] Buchacz A.: Approximate Method in Analysis of Mechatronic System Modelled by Hypergraphs. Journal of Proceedings of $18^{\text {th }}$ International Science-Technical Conference-Mašinostroenie i Technosfera XXI. Veka, Vol. 4, Donetsk (2011), p. 34-38.

[18] A. Buchacz: Formulating of Diverse Task of Chosen Class of Vibrating Mechatronic Systems. Mechanics and Mechanical Engineering, Technical University of Lodz, Vol. 15, No. 4 (2011), 31-41.

[19] A. Buchacz: Introduction to synthesis of the torsional vibrating discrete-continuous mechatronic systems by means the hypergraph and structural numbers method. Journal of Vibroengineering, Vol. 14, Issue 2, 2012, pp. 514-519, ISSN 1392-8716.

[20] A. Buchacz: Transformations of hyperaphs of subsystems of complex beam-systems as models to their synthesis. DES CADRES D'INGÉNIEURS CONTEMPORAINS, Recueil des exposés des participants du VI Conference Internationale scientifique et méthodique, du 11-18 octobre 2012 à Djerba (Tunisie), Donetsk (2012), p.7-10.

[21] A. Buchacz: Exact and Approximate Methods of Synthesis of Mechatronic Systems. Journal of Proceedings of $20^{\text {th }}$ International Science-Technical Conference-Mašinostroenie i Technosfera XXI. Veka, Vol. 3, Donetsk (2013), p. 207-210.

[22] A. Buchacz: The Selected Methods of Modeling and Analysis in Synthesis of the Transverse Vibrating Discrete-Continuous Mechatronic Systems. DES CADRES D'INGÉNIEURS CONTEMPORAINS, Recueil des exposés des participants du VII Conference Internationale scientifique et méthodique, du 7-17 Octobre 2013 à Sousse (Tunisie), Donetsk (2013), p.7-10.

[23] A. Buchacz: Alghoritm of Exact Methods Obtaining of the Solution and Dynamical Flexibilities of Subsystem of the Mechatronic system. PAMM- Proc. Appl. Math. Mech. 13, p. 513 - 514 (2013) Wiley-VCH Verlag GmbH \& Co. KGaA, Weinheim, Published online: 22 Dec 2014 / DOI: 10.1002/pamm.201410244

[24] A. Buchacz A: Dynamical Charactersitics of the Discrete Continuous Mechatronic System Obtained by Means of Exact and Approximate Methods. Selected, peer reviewed papers from the Innovative Manufacturing Enginaeering Conference 2014 (IManE 2014) Republic Moldova, Applied Mechanics and Materials,Vol. 657 (2014) pp 659-663 (C) (2014) Trans Tech Publications, Switzerland doi: 10.4028/www. scientific. net/ AMM.657.659

[25] A. Buchacz: Dynamical characteristics of diverse vibrating subsystems of complex mechanical systems. $1^{\text {st }}$ International Conference on Advances in Vibrations, Faculdade de Engenharia da Universidade do Porto (FEUP), 30 March - 1 April 2015, p.33-34. http://conference.mercatura.pt/ vibrations2015/detalhesArtigo.php? codArtigo $=8904$

[26] A. Buchacz: Determining of Characteristics of Susbsystems of Mechatronic System by Exact and Approximate Methods and Their Correction. $18^{\text {th }}$ International Conference on Composite Structures. Lisboa, 15 July - 18 July, p.270.

[27] J. Callahan, H. Baruh: Vibration monitoring of cylindrical shells using piezoelectric sensors". Finite Elements in Analysis and Design 23 (1996), 303-318.

[28] W. Kurnik: Damping of mechanical vibrations utilizing shunted piezoelements. Machine Dynamics Problems 2004, Vol. 28, No 4, 15-26.

[29] P. Lu, K. H. Lee, S. P. Lim: Dynamical Analysis of a Cylindrical Piezoelectric Transducer". Journal of Sound and Vibration (2003) 259(2), 427-443.

[30] J. Wojnarowski, A. Buchacz.: Use of hypergraphs and complete structural numbers in the analysis of vibrating eam systems with non-linearly changing cross-sections. VIBRATION ENGINEERING, 3, 4, 593-598, Hemisphere Publishing Corp., 1989. 